\title{
VANGUARDA POÉTICA EM PORTUGAL
}

\author{
Claudio Alexandre de Barros Teixeira ${ }^{1}$
}

RESUMO: O movimento da Poesia Experimental Portuguesa (PO-EX), na década de 1960, fez uma releitura criativa da herança cultural barroca, ao mesmo tempo em que dialogou com formas e procedimentos da vanguarda internacional (e em particular com a Poesia Concreta), visando a reinvenção da escrita, mesclando recursos da literatura, da música, da pintura e outras formas de expressão.

ABSTRACT: The Portuguese Experimental Poetry movement (PO-EX) performed in the 1960's a creative re-reading of the baroque cultural heritage, and at the same time established a dialogue with forms and procedures of the international vanguard (especially with Concrete Poetry), pursuing the "reinvention of the writing", merging resources of literature, music, painting and other forms of expression.

PALAVRAS-CHAVE: Experimentalismo - vanguarda - neobarroco - labirinto visualidade.

KEY-WORDS: Experimentalism — vanguard — neobaroque — labyrinth — visuality

O conceito de vanguarda sempre esteve associado ao de ruptura com a tradição, compreendida como repertório de formas históricas superadas pela evolução tecnológica e pelo sentimento de mundo das novas gerações. O entusiasmo pela sociedade urbana e industrial, pelas máquinas, pela velocidade e pelos novos meios de comunicação e de transporte, nas primeiras décadas do século XX, motivou a exigência de "uma arte verbal completamente nova", conforme escreve Marjorie Perloff em $O$ momento futurista - avant-garde, avant-guerre e a linguagem da ruptura (PERLOFF, 1993, p.116). O “discurso tradicional”, prossegue a autora, não podia transportar-se "para essa nova linguagem de telefones, fonógrafos, aeroplanos, cinema, o grande jornal" (idem). Havia um descompasso entre a sociedade moderna e as "formas canônicas do passado", que correspondiam a um certo "estado do mundo" e cuja "carga crítica implícita" e "grau de novidade" estariam "perdidos para sempre", segundo escreveu o poeta e crítico uruguaio Eduardo Milán no ensaio Poesia: questão de futuro (MILÁN, 2002, p.72).

1 Mestre em Literatura Portuguesa pela Universidade de São Paulo. 
A revolta da modernidade contra os modelos estéticos estabelecidos pela tradição, bem como "o desejo de criar novas formas e incorporar novos temas, característica que vem motivando os artistas ocidentais desde o tempo de Baudelaire" (KOSTELANETZ, 1967, p.9), levou os criadores modernos a recusarem a estabilidade, o imobilismo e a repetição em favor do inesperado, do imprevisível, do ignorado, compreendido como informação estética nova por autores como Abraham Moles, para quem a "medida da quantidade de informação" encontra-se "reduzida à medida da imprevisibilidade, isto é, a uma questão de teoria das probabilidades" (MOLES, 1969, p.36). A "medida da informação", diz Moles, "deve ser baseada na originalidade e não na significação" (idem, p.41). O novo seria, portanto, o inesperado formal, aquilo que surpreende a percepção estética do espectador, por encontrar-se fora de uma cadeia previsível de fenômenos ${ }^{2}$.

O desejo de criar novas estruturas formais, observa Richard Kostelanetz, é cúmplice do próprio devir temporal, pois acompanha processos históricos como "a I Guerra Mundial, a Depressão, a II Guerra Mundial - uma era de arte chegou a um fim somente para ser seguida, em todas as artes, por estilos consideravelmente diferentes" (KOSTELANETZ, 1967, p. 9). Neste aspecto, prossegue o ensaísta norte-americano, “o século XX sintetiza toda a história da arte”, e cita o historiador cultural Meyer Schapiro, para quem “importantes mudanças econômicas e políticas... são geralmente acompanhadas ou seguidas por mudanças nos centros da arte e em seus estilos" (idem). Com efeito, as transformações ocorridas na sociedade européia entre o final do século XIX e o início do XX foram decisivas para o surgimento das primeiras vanguardas artísticas, que, em dialética contínua com a história, aliaram o projeto da revolução estética a uma expectativa de profundas mudanças sociais, o que André Breton sintetizou em sua conhecida fórmula de que era preciso unir o "mudar a vida" de Rimbaud ao "mudar o mundo" de Marx.

2 Segundo Abraham Moles, "previsibilidade é a capacidade que tem o receptor de saber, na ordem de desenvolvimento da mensagem, quer seja temporal ou espacial, o que se seguirá a partir do que foi transmitido, de extrapolar a série temporal ou espacial dos elementos da mensagem (Wiener), de imaginar o futuro de um fenômeno a partir do seu passado. Esta previsibilidade só pode ser evidentemente de natureza estatística, não tendo um aspecto absoluto e sim quantitativo; há um grau de previsibilidade que não é outra coisa senão um grau de coerência do fenômeno, uma taxa de regularidade" (MOLES, 1969: 100). Partindo das concepções de Moles, o poeta experimental português Antônio Aragão afirma: "podemos dizer que a aventura artística caminha sempre do improvável ao possível, constantemente fazendo e refazendo este longo caminho inesgotável de previsões e imprevistos. Exatamente por isso a arte surge como um jogo necessário onde as possibilidades são incontáveis. Pelo que o acaso entra no jogo e tem uma contínua importância subjacente." (in HATHERLY, 1981, p. 103) 
Esta era a conviç̧ão que animou artistas e escritores das décadas de 1910 e 1920, como Apollinaire, Maiakovski, Duchamp ou Picabia, que alimentavam a "fé numa revolução próxima que fundiria arte, política e tecnologia" (PERLOFF, 1993, p. 73). O “momento futurista", expressão aliás criada por Renato Poggioli em Teoria dell'arte di avanguardia, correspondeu a uma "breve fase utópica do modernismo inicial, quando os artistas se sentiram às vésperas de uma nova era, que seria mais excitante, mais promissora e mais inspiradora do que qualquer outra precedente" (PERLOFF, p. 1993: $80)$.

Ou ainda, como escreveu Ana Hatherly no ensaio A reinvenção da leitura: "A depuração que os movimentos de vanguarda (...) têm procurado exercer no campo da literatura e das artes é o reflexo da mudança que se opera e se quer implantar na sociedade em que se produz" (HATHERLY, 1981, p. 150). "A literatura de vanguarda, que surge na sociedade burguesa, é antiburguesa", diz a autora portuguesa. "Insurge-se 'contra a literatura' na medida em que esta reflete, ilustra a decadência da classe dominante, que dela se apropriou, tornando-a inoperante pelo uso rotineiro, institucionalizado, que é o da cultura oficial” (idem, p 150-151). A insurgência das vanguardas contra a cultura burguesa logo assumiu o aspecto da militância política comunista ou fascista, expressões opostas do mesmo ideal de virar o mundo pelo avesso.

O teórico italiano Renato Poggioli, escrevendo sobre os elementos típicos do espírito vanguardista, cita o "antagonismo: age-se contra alguma coisa ou contra alguém" (por exemplo, o estado, a burguesia, as instituições acadêmicas); o "culto da juventude" (identificada com a vitalidade, a energia, a oposição ao antigo); e a preponderância da poética sobre a obra" (ECO: 1991, p. 93), ou seja, as teses defendidas nos manifestos e a concepção revolucionária da obra artística eram mais importantes do que a própria obra. A esse respeito, Umberto Eco faz uma importante distinção entre vanguarda e experimentalismo, em seu livro Sobre os espelho e outros ensaios: "O experimentalismo joga com a obra em si, da qual qualquer um poderá extrapolar uma poética, mas que vale antes de mais nada como obra" (idem), enquanto a vanguarda "joga com o grupo de obras ou de não-obras, algumas das quais são meros exemplos de poética" (idem). A conclusão do autor italiano, concisa e severa, é que "no primeiro caso, da obra extrapola-se uma poética; no segundo caso, da poética extrapola-se a obra" (idem). A partir da definição de Eco, podemos considerar os Cantos de Pound ou o Finnegans Wake de Joyce como obras experimentais, já que tendem a uma 
"provocação interna à história de determinada instituição literária (romance como antiromance, poesia como não poesia)" (idem, p. 93-94). Já os manifestos de Marinetti pertencem à vanguarda, pois visam uma "provocação externa, isto é, quer que a sociedade como um todo reconheça a sua proposta como um modo ofensivo de entender as instituições culturais, artísticas e literárias" (idem) ${ }^{3}$.

Em ambos os casos, porém, a contestação está presente, seja no aspecto de ativismo, que Poggioli define como "entusiasmo, fascínio pela aventura, gratuidade de fins", seja no aspecto de niilismo, ou "desprezo pelos valores correntes" e vontade de "por abaixo os obstáculos tradicionais" (idem, p. 93). O ativismo das tendências surgidas nas décadas de 1910 e 1920 - futurismo, dadaísmo, surrealismo etc — esgotou-se, porém, nas décadas subseqüentes, em grande parte devido a fatores políticos: a perseguição efetuada aos artistas inovadores pelos regimes políticos totalitários e a devastação causada pela II Guerra Mundial. A primeira onda da vanguarda teve o seu fim causado pela mesma tecnologia, energia e militarismo saudados em seus manifestos.

Após um período de novo realismo social, no pós-guerra, ativo especialmente no romance e no cinema, a segunda metade do século XX assistiu a uma nova onda de movimentos vanguardistas ou experimentais nas décadas de 1950-1970, com a Poesia Concreta, a Language Poetry, o Neobarroco latino-americano, o Oulipo francês e o Experimentalismo Poético Português $(P O-E X)$, que retomaram a retórica, a pesquisa formal e o espírito utópico de seus antecessores, mas num contexto histórico distinto e aplicando diferentes vias de elaboração formal. Não é nosso propósito discutirmos cada uma dessas tendências, mas fazermos um paralelo entre o Experimentalismo Poético Português e as vanguardas históricas para apontarmos a sua condição de singularidade.

O movimento da $P O-E X$ surge numa época conturbada pela Guerra Fria, marcada por eventos como Guerra do Vietnã, os movimentos feministas e estudantis, a luta contra a discriminação racial, a expansão da contracultura e da música pop, a divulgação de filosofias orientais e por acontecimentos tecnológicos como as viagens espaciais. Portugal vivia então numa das últimas ditaduras de direita da Europa, comandada por Antônio Salazar (o outro regime autoritário era o de Francisco Franco, na Espanha), que

3 A distinção entre experimentalismo e vanguarda não é aceita por autores como E. M. de Melo e Castro, para quem a poesia experimental "se preocupa com as bases e a evolução do ato poético e do poema como objeto. O estudo do resultado das experiências realizadas é fundamental. Nesse estudo reside de fato o valor de projeção do ato criador experimental. Por ele a poesia experimental é sinônimo de Arte de Vanguarda" (HATERLY, Ana e MELO E CASTRO, E. M.:1981, p. 109). 
sonhava em manter o domínio colonial em países como Angola e Moçambique e preservar um sistema nacionalista, messiânico e militarista, há muito anacrônico no continente europeu.

Conforme diz Ana Hatherly, no livro Um calculador de improbabilidades, os poetas e intelectuais portugueses sentiram "uma premente necessidade de mudança e de abertura ao mundo", mas também "uma necessidade íntima de rigor, de transparência e de audácia incomuns nesse tempo" (HATHERLY, 2005, p. 8-9). A PO-EX, prossegue a autora, "reflete essa conjuntura e ilustra-a à sua maneira, ao assumir uma postura de insubordinação estética e cívica", característica de todas as tendências de vanguarda do século XX, mas é um fenômeno "peculiar na medida em que foi simultaneamente uma revolta contra o status quo local e a integração numa recusa dos valores de um establishment internacional, que se tornara intolerável para os jovens de então" (idem). O sentimento de desconforto em relação ao regime salazarista e o desejo de manifestar o repúdio na forma de uma arte inovadora foram essenciais à definição dos vetores estéticos e ideológicos da $P O-E X$, que tem como marcos fundadores os lançamentos das revistas Poesia Experimental, em 1964, e Operação, em 1967, além de happenings como o Concerto e Audição Pictórica (1965), a exposição coletiva VisoPoemas (1965) e a Conferência Objeto (1967), que reuniram poetas, músicos e artistas visuais.

O caráter provocativo e performático desses eventos é herdeiro do espírito de transgressão das vanguardas históricas, presente na leitura do "extenso poema sonoro" Zang Tumb Tuuum por Marinetti, que "explora a capacidade do perfomer para usar a voz, gesto e entonação", conforme diz Marjorie Perloff em O momento futurista (PERLOFF, 1993, p. 119), ou ainda nas intervenções de Maiakovski nos cabarés de Moscou, em que o poeta se apresentava com as faces pintadas ou com a célebre gravata amarela, conforme relata Angelo Maria Ripellino em Maiakovski e o teatro de vanguarda (1971). No Concerto e Audição Pictórica, realizado em Lisboa, em 1965, com a participação de poetas como Salette Tavares, Melo e Castro e de músicos como Jorge Peixinho, foram tocadas composições de John Cage, com a colaboração adicional de

um caixão, um piano de meia cauda, instrumentos de percussão vários, balões, metrônomos, uma harpa, um piano de criança, palavras soltas, chocalhos de várias espécies, com e sem badalo, uma flauta de bisel, uma couve, um bidê, risos, pandeiretas, música de Chopin, um ré-ré, um despertador, um rolo de papel higiênico, um jarro de água, um brinquedo de corda, 2 violinos de 
criança (brinquedos), uma máquina de barbear elétrica, um cravo (flor), uma casa de cão que ladra (brinquedo), pratos, guizos, um apito, espaço tempo, ritmo, luz, silêncio, uma pistola (brinquedo) (HATHERLY, 1981, p. 46).

Já na Conferência Objeto, realizada na Galeria Quadrante, durante o lançamento das revistas Operação 1 e 2, foi preparado um ambiente para o público que recorda a técnica da instalação, com as folhas de cartolina que compunham o primeiro número da revista "dispostas na parede como numa exposição de pintura normal, suspensas de fios de nylon, mas sem moldura" (idem, p.77), enquanto no chão da sala foram colocadas várias capas da $O P .-1$, "formando cubos em dois cantos da sala" (idem). No texto $A$ crítica então, publicado sem crédito no livro PO-EX - Textos teóricos e documentos da poesia experimental portuguesa, o autor afirma que, com tais provocações, a vanguarda portuguesa "atacou e ataca destrutivamente o código fossilizado da leitura sentimentalista e opressiva da língua portuguesa no momento preciso em que o sistema fascista dele mais se reclama", no início da década de 1960, com o objetivo de "galvanizar o povo para as guerras do Ultramar" (HATHERLY, Ana e MELO E CASTRO, E. M. 1981, p. 175-176).

A resistência estética era, em si mesma, um ato político, pois indicava outras possibilidades de comunicação e, portanto, de relacionamento entre indivíduo, sociedade, arte e história. A ruptura proposta pelos experimentalistas portugueses, porém, não significou uma recusa de toda a tradição literária, à maneira dos futuristas italianos, que opunham o automóvel à Vitória de Samotrácia e defendiam a destruição de museus e bibliotecas. Os experimentalistas recusavam a dicção lírico-discursiva, o sentimentalismo, a retórica, mas propunham o diálogo com o que houve de mais inventivo no passado.

"Nós falamos sempre em ruptura", diz Melo e Castro, "mas essa ruptura diz respeito a um convencionalismo que nos era imposto, nunca ruptura com uma tradição que era preciso reconstruir" (idem, p. 20-21). Como exemplo da reconstrução ou reinvenção do passado, diz o autor, "fomos, por exemplo, desenterrar a Poesia Barroca Portuguesa, fomos recuperar, fazer uma revisão crítica das fontes culturais que eram sistematicamente, por uma razão ou (...) sistematicamente ocultadas” (idem). E Ana Hatherly declara que "essa ruptura é uma recusa do ambiente que nos rodeia, e nunca é uma ruptura com as nossas raízes. (...) Pois, porque na verdade muitos dos meus trabalhos têm base numa espécie de quase reelaboração de maneiras de trabalhar 
antigas" (idem, p. 21). A eleição de um repertório inventivo com o qual se poderia dialogar, o repertório barroco, maneirista e dos alfabetos arcaicos, é o que distingue, essencialmente, a $P O-E X$ das vanguardas históricas, que pretendiam criar algo totalmente novo, sem raízes em nenhuma tradição. O diálogo com o barroco, e com a forma do labirinto poético em especial, foi decisivo para a evolução do trabalho poético de Ana Hatherly.

A colaboração entre poesia, música, performance e artes visuais, em direção a uma "arte total" que unisse as diferentes formas de expressão (projeto que tem como antecessores a missa barroca, o drama musical wagneriano e manifestações das vanguardas históricas, e que assumiria novas feições com a proposta concretista da linguagem verbivocovisual, neologismo criado por James Joyce e adotado no PlanoPiloto da Poesia Concreta) foi uma das preocupações centrais da PO-EX. Para a realização dessa ousada aventura que hoje nós chamaríamos de multimídia, no entanto, os experimentalistas contavam com extrema carência de recursos, compensada pelo esforço imaginativo.

"Uma das características fundamentais da Poesia Experimental Portuguesa é a sua escassez de meios", afirmou Melo e Castro numa mesa-redonda realizada na Bienal de São Paulo, em 1977 (HATHERLY, Ana e MELO E CASTRO, E. M., 1981, p. 24). "Nós trabalhamos sempre com meios pobres, (...) com coisas feitas à mão por nós próprios, nunca tivemos acesso a mecanismos sofisticados — foi assim que nós enfrentamos a era eletrônica e a era cibernética" (idem). Apesar disso, os experimentalistas mantiveram-se bem-informados sobre o que havia de mais avançado na época, desde a teoria da informação, o estruturalismo, a semiótica, até as pesquisas realizadas pela vanguarda internacional, e em particular com a Poesia Concreta. Os primeiros resultados apresentados pela $P O-E X$, em suas revistas e performances realizadas na década de 1960, apontam já o caminho de singularidade que seria percorrido nos anos posteriores, em que as influências concretistas foram somadas às do barroco, da caligrafia oriental e da pesquisa científica, em obras planejadas e executadas de acordo com regras específicas. Conforme escreve Ana Hatherly,

Nesse tipo de criação poética (experimental) o mais significativo fator é o da experiência (...). As regras que o poeta a si próprio impõe são as regras do jogo que ele executa e persegue com idéias, palavras e atos. A obra criadora não é tanto o poema: o poema é apenas o resultado. O mais importante é o 
conjunto de regras que o poeta a si próprio impõe, as possibilidades desse conjunto de regras (idem, p. 133).

O segundo número da revista Operação, que contou exclusivamente com poemas de Ana Hatherly, traz um detalhado programa em que a autora apresenta, de modo conciso, a experiência realizada em cada um dos poemas do ciclo. Assim, por exemplo, ela define o "Tipo A" como "deslocação semântica de uma palavra privilegiada num contexto"; o "Tipo E" seria a "deslocação por metáfora e metonímia", e assim por diante (HATHERLY, 2001, p.71). Esse tipo de programa é essencial ao projeto experimentalista, pois evita a leitura caótica, dispersiva, sem limites de interpretação. A obra poética experimental, concebida a partir de regras específicas, concilia a pluralidade de leituras com um planejamento rigoroso efetuado pelo poeta, que está mais preocupado com o processo criativo do que com a obra acabada.

A visão estratégica da operação poética experimental, sem dúvida, afasta-se do subjetivismo expressionista, da retórica futurista, da anarquia dadá e do automatismo surrealista, aproximando-se das realizações do construtivismo russo e da noção do poema como estrutura defendida pelos poetas brasileiros do grupo Noigandres. A relação entre a $P O-E X$ e a Poesia Concreta, porém, não foi de adesão incondicional e continuidade, havendo mesmo um momento de ruptura, no caso de Ana Hatherly, que agora vamos examinar. No ensaio $A$ reinvenção da leitura, a autora reconhece que o movimento da Poesia Concreta "é fundamental para a evolução da leitura na medida em que contribui para que o texto deixe de ser apenas uma expressão lírico-literária para se tornar por fim uma pura combinação de sinais, estabelecendo desse modo uma nova trajetória da palavra para o signo", alargando o âmbito de leitura "para fora dos limites literários tradicionais" (HATHERLY, Ana e MELO E CASTRO, E. M.: 1981, p. 147148).

No entanto, "ao pretender que o poema concreto fosse imediatamente legível (...), isto é, sem a intervenção duma leitura decifradora, os seus teorizadores condenavam-no ao esgotamento imediato" (idem, p. 144). Os ideais de objetividade e rapidez comunicativa da Poesia Concreta, que dialogou com a linguagem do jornal, do jingle, do outdoor, contrastava com a poesia mais cifrada, enigmática ou barroquista da poeta portuguesa, que por vezes se aproxima de uma deliberada abstração plástica, como nos Mapas da imaginação e da memória, no romance visual $O$ escritor, em Leonorana e outras obras. "Para os concretistas europeus, sobretudo os germânicos e os anglo- 
saxãos", escreve Ana Hatherly, "a importância do aspecto formalmente visual acaba por impor-se e até sobrepor-se ao aspecto literário" (idem, p. 144), reatando as relações com uma "tradição da vanguarda (embora esses termos possam parecer incompatíveis) em que língua, som, imagem se confundem, derrubando declaradamente as fronteiras entre as artes" (idem).

Como resultado da primazia estratégica do grafismo sobre a referencialidade, prossegue a autora, desenvolveram-se outras modalidades de poesia experimental, como “o poema visual, (...); a poesia objetiva, que implica a realização de objetos tridimensionais e a colaboração de músicos; (...); a poesia cinética ${ }^{4}$, tátil etc.” (idem, p. 147), até se alcançar o limite extremo da poesia-espetáculo, que se liga ao happening" (idem).

Antônio Aragão, poeta que participou ativamente do movimento da $P O-E X$, relata a experiência pioneira que realizou no campo da poesia eletrônica, com a colaboração do italiano Nanni Balestrini e de um computador da IBM, que resultou na criação de mais de três mil variações do mesmo grupo de versos. Aragão afirma, no artigo $A$ arte como campo de possibilidades (que evidencia, já no título, o vínculo com a teoria de Abraham Moles), que "a regra de partida forneceu um princípio que originou a possibilidade. Em seguida, o cérebro IBM tentou todas as combinações” (idem, p. 105). Segundo o poeta português, "é indiscutível o alto nível lírico de alguns poemas. Aqui o homem fabrica o próprio calculador de possibilidades colocando-se depois como fruidor atento perante o milagre do imprevisível" (idem). A experiência pioneira desenvolvida por Aragão, numa época em que era muito difícil o acesso a sistemas de informática, teve um extraordinário desenvolvimento nas décadas posteriores, graças à revolução tecnológica, que favoreceu o surgimento da nova poesia eletrônica, ou infopoesia, que tem hoje, entre seus expoentes, o português E. M. de Melo e Castro e os brasileiros Augusto de Campos, Arnaldo Antunes, Elson Fróes e André Vallias.

As mídias eletrônicas oferecem suportes dinâmicos e interativos no ambiente da internet, que realiza o sonho das vanguardas históricas de unir o som, a imagem, a

4 Conforme Melo e Castro, a poesia cinética "propõe uma noção de sintaxe dinâmica, isto é, de uma possível e exeqüível modificação das relações entre os elementos simples que constituem as estruturas dos poemas, indo até a sua total modificação ou mesmo destruição - caso o utente do poema cinético o deseje. O caráter efêmero dos materiais em que estão realizados os poemas (papel e cartão) implica justamente que eles, sendo uma evolução dinâmica do 'livro', convidam muito mais a uma utilização, a um consumo e por fim a uma destruição orgânica, que a uma simples leitura ou percepção visual" (HATHERLY, Ana e MELO E CASTRO, E. M., 1981, p. 159-160 ). 
palavra e o movimento, transcendendo as fronteiras nacionais e os limites da escrita ou ainda ampliando a noção de escrita para além do seu sentido convencional, como Ana Hatherly prenunciou em seus labirintos visuais, como O escritor e os Mapas da imaginação e da memória, realizados nas décadas de 60 e 70 com notória carência de recursos materiais.

Neste sentido, podemos considerar que a era tecnológica, ao potencializar os aspectos sonoros, imagéticos e dinâmicos da linguagem, confirma as profecias da autora portuguesa, para quem “A noção de ESCRITA alargou-se / a TUDO / a QUASE TUDO / porque a escrita é sinônimo de IMAGEM / imagem para se ver / para se ter / para se ser / Escrevo para compreender / para apreender: / a escrita é o que me revela / um mundo / o mundo" (HATHERLY, 2005, p. 58). As novas tecnologias, ao "reinventarem a escrita" na tela de cristal líquido, retomam, ao mesmo tempo, a antiga tradição dos calígrafos, escribas, poetas-pintores e criadores de labirintos estudados por Ana Hatherly em A experiência do prodígio, numa reconciliação entre passado e presente, tradição e modernidade.

\section{REFERÊNCIAS BIBLIOGRÁFICAS:}

CAMPOS, Augusto e Haroldo de; PIGNATARI, Décio. Teoria da Poesia Concreta. São Paulo: Duas Cidades, 1965.

CASTRO, E. M. de Melo. As fontes, as nuvens e o caos. Notas sobre o barroco, neobarroco e metabarroco na poesia portuguesa da $2^{a}$. metade do século $X X$, artigo publicado no n. $4 / 5$ da revista Claro Escuro. Lisboa: Quimera edições, 1990.

CASTRO, E. M. de Melo, e HATHERLY, Ana. PO-EX: textos teóricos e documentos da poesia experimental portuguesa. Lisboa: Moraes Editora, 1981.

ECO, Umberto. Obra aberta. São Paulo: Perspectiva, 1976.

ECO, Umberto. Sobre os espelhos e outros ensaios. Rio de Janeiro: Nova Fronteira, 1989.

HATHERLY, Ana. Um calculador de improbabilidades. Coimbra: Quimera Edições, 2001.

HATHERLY, Ana, e MELO E CASTRO, E. M. PO.EX - Teóricos e documentos da poesia experimental portuguesa (com E. M. de Melo e Castro). Lisboa: Moraes Editores, 1981.

HATHERLY, Ana. A experiência do prodígio - bases teóricas e antologia de textos visuais portugueses dos séculos XVII e XVIII. Lisboa. Imprensa Nacional - Casa da Moeda, 1983.

KOSTELANETZ, Richard. Novos rumos das artes. Rio de Janeiro: Lidador, 1967.

MILÁN, Eduardo. Estação da fábula. São Paulo: Fundação Memorial da América Latina, 2001. 
MOLES, Abraham. Teoria da informação e percepção estética. Rio de Janeiro: Tempo Brasileiro, 1969.

PERLOFF, Marjorie. O momento futurista. São Paulo: Edusp, 1993.

SILVA, Rogério Barbosa. Ana Hatherly: uma poesia em mutação. Artigo publicado na revista Et Cetera, de Curitiba, 2006, 156-161. 